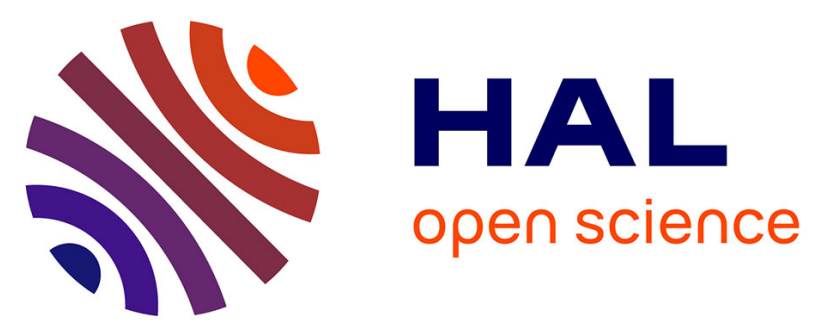

\title{
Spectroscopic Insights into the Electrochemical Mechanism of Rechargeable Calcium/Sulfur Batteries
} Antonio Scafuri, Romain Berthelot, Klemen Pirnat, Alen Vizintin, Jan Bitenc, Giuliana Aquilanti, Dominique Foix, Rémi Dedryvère, Iztok Arčon, Robert Dominko, et al.

\section{To cite this version:}

Antonio Scafuri, Romain Berthelot, Klemen Pirnat, Alen Vizintin, Jan Bitenc, et al.. Spectroscopic Insights into the Electrochemical Mechanism of Rechargeable Calcium/Sulfur Batteries. Chemistry of Materials, 2020, 32 (19), pp.8266-8275. 10.1021/acs.chemmater.0c02074 . hal-02966157

\section{HAL Id: hal-02966157 \\ https://hal.science/hal-02966157}

Submitted on 13 Oct 2020

HAL is a multi-disciplinary open access archive for the deposit and dissemination of scientific research documents, whether they are published or not. The documents may come from teaching and research institutions in France or abroad, or from public or private research centers.
L'archive ouverte pluridisciplinaire HAL, est destinée au dépôt et à la diffusion de documents scientifiques de niveau recherche, publiés ou non, émanant des établissements d'enseignement et de recherche français ou étrangers, des laboratoires publics ou privés. 


\title{
Spectroscopic insights into the electrochemical mechanism of a rechargeable calcium/sulfur battery
}

\author{
Antonio Scafuri ${ }^{a, b, c, d}$, Romain Berthelot ${ }^{b, c, e}$, Klemen Pirnat ${ }^{a}$, Alen Vizintin ${ }^{a}$, Jan Bitenc ${ }^{a}$, Giuliana \\ Aquilantif, Dominique Foix ${ }^{e, g}$, Rémi Dedryvère ${ }^{c, e, g}$, Iztok Arčon ${ }^{h, i}$, Robert Dominko ${ }^{a, c, d,{ }^{*}}$ and Lorenzo \\ Stievano ${ }^{b, c, e, *}$

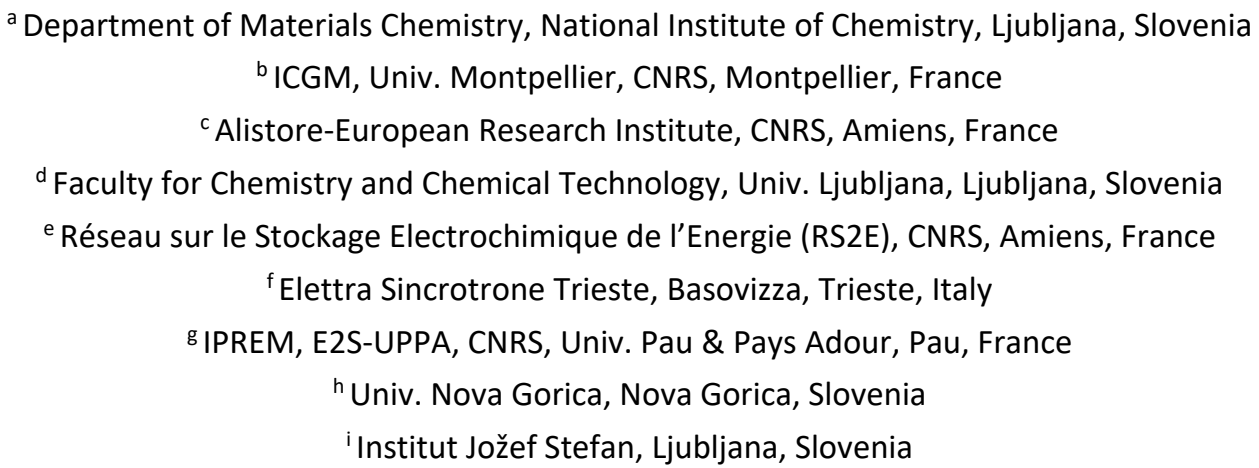

Corresponding authors: Robert Dominko (robert.dominko@ki.si) and Lorenzo Stievano (lorenzo.stievano@umontpellier.fr)

\begin{abstract}
Calcium batteries represent a promising alternative to lithium metal batteries. The combination of the low redox potential and low-cost and energy-dense calcium anode $\left(2073 \mathrm{mAh} / \mathrm{cm}^{3}\right.$, similar to $2044 \mathrm{mAh} / \mathrm{cm}^{3}$ for Li) with appropriate low-cost cathode materials such as sulfur, could produce a game-changing technology in several fields of applications. In this work, we present the reversible activity of a proof-of-concept $\mathrm{Ca} / \mathrm{S}$ battery at room temperature, characterized by a surprising medium-term cycling stability with low polarization, promoted by the use of a simple positive electrode made of sulfur supported on an activated carbon cloth scaffold, and a state-of-the-art fluorinated alkoxyborate-based electrolyte. Insights on the electrochemical mechanism governing the chemistry of the $\mathrm{Ca} / \mathrm{S}$ system were obtained for the first time by combining $\mathrm{X}$-ray photoelectron spectroscopy and X-ray absorption spectroscopy. The mechanism implies the formation of different types of soluble polysulfides species during both charge and discharge at room temperature, and the formation of solid CaS at the end of discharge. The reversible electrochemical activity is proven by the reformation of elemental sulfur at the end of the following charge. These promising results open the
\end{abstract}


way to the comprehension of emerging $\mathrm{Ca} / \mathrm{S}$ systems which may represent a valid alternative to $\mathrm{Mg} / \mathrm{S}$ and $\mathrm{Li} / \mathrm{S}$ batteries.

\section{Introduction}

Rechargeable lithium-ion batteries (LIB) have become an everyday tool that powers our portable electronic devices and significantly contributes to electrification of the transport. In half a century, LIB started from early-stage research reports to large-scale production with intensive resources exploitation and the regular announcement of gigafactory projects all over the world. Similarly to other massive production, there is now growing concerns regarding resource availabilities. ${ }^{1-3}$ Together with improving the recycling process of $\mathrm{LIB}^{4}{ }^{4}$ in this context it is important to investigate alternative strategies for efficient and more sustainable electrochemical energy storage.

In the shadow of emerging LIB during decades, the sodium-based analog systems are now under the spotlight. ${ }^{5-11}$ Their development has been eased as many similarities are shared with the Li-based systems, such as the choice of positive electrode materials (layered oxides and polyanionic compounds) and the nature of the electrolytes. Similarly, the actual steep increase of the number of research works on potassium-ion batteries testify the strong interest on these systems as viable alternatives to LIB. ${ }^{12-20}$

The storyboard appears more complicated for $\mathrm{Mg}$ and $\mathrm{Ca}$ metal batteries, which are considered as promising electrochemical systems given the abundance of the elements and their physical and chemical features that could lead to very high energy-density cells. ${ }^{21-30}$ In brief, the formation of a passive film with sluggish ion conductivity on the surface of the metal anode, the lack of solvents and salts with high voltage stability, together with problems of structure stability during the insertion of double-charge cations into crystalline hosts dramatically narrows the choice of positive electrode materials. ${ }^{31}$

Among the available cathode materials for Mg- and Ca-based batteries, those based on sulfur are in principle very promising systems. In fact, sulfur might ease the 2-electron transfer and exhibits a high specific capacity of $1675 \mathrm{mAh} / \mathrm{g}$ for the theoretical formation of MgS or CaS during the electrochemical discharge. The first rechargeable Mg-sulfur battery (MSB) was reported by Muldoon and coworkers in 2011, with only few cycles and the first evidence of intermediate formation of polysulfide species by X-ray photoemission spectroscopy (XPS). ${ }^{32}$ Since then, significant improvements have been made in the design of electrolytes being both non-nucleophilic to avoid reaction with the sulfur species and compatible with the magnesium electrode..$^{33}$ Most of them came from the group of Zhao-Karger and Fichtner, who proposed magnesium salts with alkoxyborate and alkoxyaluminate 
anions. ${ }^{34,35}$ Extended reversible electrochemical process have been then possible with $\mathrm{Mg} / \mathrm{S}$ batteries made with conventional carbon-sulfur composite electrodes, and logically so does the investigation of the overall electrochemical process by combining a wide range or characterization techniques, as it was done before for the Li/S batteries. ${ }^{30,33,36,37}$

While in a recent perspective work Monti et al. showed that $\mathrm{Ca} / \mathrm{S}$ batteries could compete with LIB with specific volumetric and specific capacities of the order of $1000 \mathrm{Wh} / \mathrm{L}$ and $570 \mathrm{Wh} / \mathrm{kg},{ }^{38} \mathrm{Ca} / \mathrm{S}$ batteries have shown until nowadays an even shorter history. ${ }^{30,39,40}$ In 2013 , See and Seshadri presented a first example of a primary Ca-sulfur battery. ${ }^{41}$ This system was not reversible given the impossibility, at that time, to obtain calcium plating during charge due to the nature of the passivation films formed on Ca metal in common organic electrolytes. ${ }^{42}$ Only in 2015, Ponrouch and coworkers put back on stage classical type of electrolytes with carbonate-based solvents and $\mathrm{Ca}\left(\mathrm{BF}_{4}\right)_{2}$ salt showing reversible calcium deposition and stripping at relatively high temperatures $\left(75-100{ }^{\circ} \mathrm{C}\right) .4^{43,44}$ This seminal work was followed by the work of the group of Bruce who developed a $\mathrm{Ca}\left(\mathrm{BH}_{4}\right)_{2}$-based electrolyte suitable for application at room temperature. ${ }^{45}$ However, in both cases the calcium deposition comes along with by-products $\left(\mathrm{CaF}_{2}\right.$ or $\mathrm{CaH}_{2}$, respectively) indicating that these electrolyte formulations deserve more optimization. On top of that, these electrolytes are also not adapted for sulfur-based composite electrodes.

In 2019, Manthiram and coworkers proposed a reversible $\mathrm{Ca} / \mathrm{S}$ battery through a Li-ion mediation concept with an electrolyte combining calcium and lithium triflate salts in tetraglyme solvent. The addition of lithium triflate enables a better first discharge capacity and more importantly seems to trigger the reversibility of the overall process in the subsequent cycles. After 20 cycles at $\mathrm{C} / 10$, a promising capacity around $300 \mathrm{mAh} / \mathrm{g}_{\mathrm{s}}$ is achieved. ${ }^{46}$ Nevertheless, in spite of its certain fundamental interest, such a dual-ion concept still depends on the use of lithium and have thus only limited application perspectives.

More recently, the group of Zhao-Karger and Fichtner, shortly followed by those of Nazar and Liu, proposed a new calcium alkoxyborate salt able to plate and strip calcium at room temperature. ${ }^{47-49}$ This salt that can be considered as the initiator of a new generation of non-nucleophilic calcium electrolyte salts working at room temperature, ${ }^{50}$ which are expected to be adapted to sulfur-based cathode systems, Indeed, a first example of rechargeable $\mathrm{Ca} / \mathrm{S}$ has been published the end of the review process of the current work. ${ }^{51}$

In this work, first we confirm the electrochemical activity of $\mathrm{Ca} / \mathrm{S}$ battery at room temperature using the above-mentioned alkoxyborate-based electrolyte and a composite positive electrode made from sulfur-impregnated activated carbon cloth (ACC), in agreement with the recent results of Li et al. ${ }^{51}$ 
Moreover, by using a combination of in situ and ex situ spectroscopic techniques such as X-ray absorption (XAS) and X-ray photoemission (XPS) spectroscopy we propose a clear view of the electrochemical mechanisms, which proceed through the formation of several calcium polysulfide species to calcium sulfide as end of discharge product.

\section{Materials and methods}

Calcium salt synthesis, electrolyte formulation and electrochemical cell assembly were carried out into Ar-filled glovebox $\left(\mathrm{H}_{2} \mathrm{O}\right.$ and $\mathrm{O}_{2}$ contents $<0.5 \mathrm{ppm}$ ). Hexafluoroisopropanol (purity $>99 \%$ ) was purchased from Apollo Scientific, treated with Ar to remove air before being transferred inside glovebox and lastly dried two times with activated $4 \AA$ A molecular sieves for a period of 10 days to end up with a low amount water than $0.1 \mathrm{ppm}$ (as estimated by Karl-Fisher titration). Calcium borohydride bis(tetrahydrofuran) ( $\mathrm{Ca}\left(\mathrm{BH}_{4}\right)_{2} \cdot 2 \mathrm{THF}$, purity $\left.99.7 \%\right)$ was purchased from Sigma-Aldrich and used as received. Dimethoxyethane (DME, purity $>99 \%$ ) was purchased from Sigma-Aldrich. To ensure an efficient drying, argon bubbling was firstly carried out before transfer to the glovebox. The solvent was further dried using a $4 \AA$ molecular sieves for 3 days, and lastly refluxed with $\mathrm{K} / \mathrm{Na}$ (3/1 wt.\%) for 1 day and finally distilled. Karl-Fisher titration operated in glovebox gave a value of $3.1 \mathrm{ppm}$ of $\mathrm{H}_{2} \mathrm{O}$.

Calcium tetrakis(hexafluoroisopropyloxy)borate $\left(\mathrm{Ca}\left[\mathrm{B}(\mathrm{hfip})_{4}\right]_{2}\right)$ was prepared by adapting the original protocol of Zhao-Karger and coworkers, ${ }^{47}$ as already reported in a parallel work on organic positive electrodes for calcium batteries. ${ }^{52}$ In brief, to the $\mathrm{Ca}\left(\mathrm{BH}_{4}\right)_{2} 2 \mathrm{THF}$ powder $(1.07 \mathrm{~g} ., 5 \mathrm{mmol})$ dissolved in $10 \mathrm{ml}$ of anhydrous DME, anhydrous hexafluoroispropanol $(42.5 \mathrm{mmol}, 4.5 \mathrm{ml}, 7.14 \mathrm{~g}$.) was slowly added dropwise, and the resulting solution was stirred at room temperature for 20 hours. After solvent evaporation at reduced pressure, a white powder of $\mathrm{Ca}\left[\mathrm{B}(\mathrm{hfip})_{4}\right]_{2}$ was obtained by drying at $50{ }^{\circ} \mathrm{C}$ under vacuum. The final electrolyte was obtained by dissolving the as-prepared calcium salt in dried DME, with a final concentration of $0.5 \mathrm{~mol} / \mathrm{L}$. Reversible calcium deposition and stripping at room temperature was confirmed by 3-electrode electrochemical test with several types of working electrodes. ${ }^{52}$

Carbon/sulfur composite obtained by sulfur impregnation of activated carbon cloth are widely used electrodes for investigating emerging metal/sulfur batteries. ${ }^{35,53-55}$ Here the impregnation process follows well-established protocols. In brief, $8 \mathrm{~mm}$ diameter discs of activated carbon cloth (ACC 50720 from Kynol Europa $\mathrm{GmBH}$ ) were first punched out and dried at $120^{\circ} \mathrm{C}$ for 4 hours under primary vacuum. Sublimed sulfur powder was then homogeneously dispersed on top of the disks, which here then heated up in a stainless steel container at $155^{\circ} \mathrm{C}$ for 16 hours with a heating rate of $0.2^{\circ} \mathrm{C} \mathrm{min}^{-1}$. After cooling down, the electrodes were lastly heated under argon flow at $200^{\circ} \mathrm{C}$ for 50 minutes to 
sublimate the sulfur not adsorbed on the cloth. The sulfur content in these ACC/S electrodes was estimated by thermogravimetric analysis to be around $10 \mathrm{wt}$. \%, giving a corresponding sulfur loading of the electrodes of $0.8-1 \mathrm{mg} \mathrm{cm}^{-2} .55$

Galvanostatic tests were carried out in stainless-steel coin cells (CR2032, 316L). The nature of the calcium anode strongly influences the electrochemical performance. First unsuccessful attempts used millimetric calcium granules (Alfa Aesar) hammered and then surface scratched to get very thick pieces (roughly $1 \mathrm{~mm}$ ). Our most promising results reported here were obtained with calcium foils from $\mathrm{ACl}$ Alloys ( $0.5 \mathrm{~mm}$ thick, 99 "purity), which native surface oxidation layer was however removed with a scalpel before use in order to obtain a shiny metal surface. Coin-cells were assembled in an argon-filled glove-box with two glass fiber membrane separators (Whatman, GF/A) wetted with $80 \mu \mathrm{l}$ of electrolyte. The cells were cycled using research-grade potentiostats (Bio-Logic) at room temperature between 0.5 and $3.5 \mathrm{~V}$ with current density of $\mathrm{C} / 10$ (approximately $167 \mathrm{~mA} / \mathrm{gs}_{\mathrm{s}}$ ).

X-ray photoelectron spectroscopy (XPS) analyses were carried out ex situ with a Thermofischer Scientific ESCALAB $250 \mathrm{Xi}$ spectrometer using focused monochromatized Al Ka radiation ( $\mathrm{hv}=1486.6 \mathrm{eV})$. The spectrometer is equipped with an argon glovebox $\left(<1 \mathrm{ppm} \mathrm{O}_{2},<1 \mathrm{ppm} \mathrm{H}_{2} \mathrm{O}\right)$ directly connected to the analysis chamber in order to preserve the chemical composition of the electrodes surface. For the same reason, no sputtering was used to clean the samples surface. The analyzed surface area of the samples was a $650 \mu \mathrm{m}$ diameter disk. $\mathrm{Ca} / \mathrm{S}$ cells were stopped at different points of the first discharge/charge cycle (one for each point, see Figure S1) and disassembled in an argon glovebox. At any step of the samples preparation, they were never in contact with air.

The XAS measurements were performed at the XAFS beamline of synchrotron Elettra (Basovizza Trieste, Italy). ${ }^{56}$ The X-ray absorption spectra were recorded at the both sulfur and calcium K-edge in fluorescence-detection mode. A Si(111) double-crystal monochromator was used with about $0.3 \mathrm{eV}$ resolution at $2.5 \mathrm{keV}$. Higher-order harmonics were effectively eliminated at the S K-edge by using a double-flat silica mirror placed at a grazing angle of $8 \mathrm{mrad}$, whereas a detuning of $60 \%$ was used to eliminate the harmonics at the Ca K-edge. The intensity of the monochromatic X-ray beam before the sample was measured by an ionization chamber detector, filled with a mixture of $30 \mathrm{mbar}$ of $\mathrm{N}_{2}$ and 1970 mbar of He. The fluorescence signal was detected with a silicon drift detector (KETEK GmbH AXAS-M with an area of $80 \mathrm{~mm}^{2}$ ). In situ and ex situ Ca and S K-edge XAS spectra were measured from -150 to $300 \mathrm{eV}$ relative to the respective absorption edge energy (2472 and $4038 \mathrm{eV}$ for S and Ca Kedge, respectively). In the near-edge (XANES) region, equidistant energy steps of $0.2 \mathrm{eV}$ were used, with an integration time of $5 \mathrm{~s}$ per point. The measuring time was $60 \mathrm{~min}$ per spectrum. Operando XAS spectra were measured continuously only at the S K-edge in the range from -35 to $150 \mathrm{eV}$ relative to the S K-edge (28 min per spectrum) along a full discharge/charge cycle at $\mathrm{C} / 25(25 \mu \mathrm{A})$, corresponding 
to the reaction of one mole of Ca per mole of $\mathrm{S}$ in 25 hours. A specifically designed in situ cell previously described was used for the operando measurement. ${ }^{57}$ The operando spectra were collected on the back of a self-supported ACC/S in contact with a $8 \mu \mathrm{m}$ thick beryllium window which also worked as the current collector for the positive electrode. The operando XAS spectra were first globally analyzed by a statistical tool named Principal Component Analysis (PCA), and the number of principal components determined in this way was used as the basis for Multivariate Curve ResolutionAlternating Least Squares (MCR-ALS) analysis, which allows the stepwise reconstruction of the spectral components which are necessary for interpreting the whole multiset of operando spectra. ${ }^{58,59}$ The PCA analysis was first applied to the discharge and the charge processes separately, and then to the whole discharge/charge cycle. The MCR-ALS analysis was performed with the following constraints: (i) nonnegativity of the intensity and of the concentration of all the components, (ii) unimodality for all components in the case of discharge and charge taken separately, and limited to some of the needed components for the whole cycle, (iii) closure (sum of the components always equal to $100 \%$ of the intensity). The reconstructed spectral component were then interpreted as regular normalized XANES spectra and manipulated using the IFEFFIT software. ${ }^{60}$

\section{Results and discussion}

Figure 1a shows the galvanostatic cycle at $\mathrm{C} / 10$ of a proof-of-concept $\mathrm{Ca} / \mathrm{S}$ coin cell built with a $\mathrm{Ca}$ metal negative electrode, an ACC/S positive electrode and a $0.5 \mathrm{M} \mathrm{Ca}\left[\mathrm{B}(\mathrm{hfip})_{4}\right]_{2} / \mathrm{DME}$ electrolyte. The discharge is characterized by two well-defined plateaus at 2.25 and $2 \mathrm{~V}$ (also underlined by the derivative curve in Figure $1 \mathrm{~b}$ ), followed by a sloping profile down to $0.5 \mathrm{~V}$. The values of the plateaus differ from Li-sulfur batteries for approximately $150 \mathrm{mV}$, in the agreement with the difference in standard redox potential of lithium and calcium. Moreover, potential values are significantly higher than those observed by See et al. during their unique discharge with electrolytes based on perchlorate salt, ${ }^{41}$ but also than those of the first discharge obtained by Manthiram et al. with a Li/Ca-triflatebased electrolyte. ${ }^{46}$ There are however in fairly good agreement with the galvanostatic profile recently reported by Li et al., ${ }^{51}$ confirming the low overpotential for stripping of calcium in alkoxyborate-based electrolyte. ${ }^{47,48,52}$

The initiation of the subsequent charge starts at well-defined potential at approximately $2.4 \mathrm{~V} v \mathrm{~s}$. calcium metal anode however it jumps quickly to higher potential of $2.55 \mathrm{~V}$, and the second half of the charge evolves through a sloping trend up to $3.5 \mathrm{~V}$. Shift of the potential at the beginning of oxidation process is most likely connected with the increase of polarization on the anode as shown by experiment in three electrode cell set-up in the case of organic positive electrodes. ${ }^{52}$ In the 
subsequent cycles, the galvanostatic profile is continuously altered especially during the discharge processes with the apparition of a strong activation process connected with stripping process on the calcium anode and the gradual loss of the two plateaus. ${ }^{52}$

The evolution of the discharge and charge capacities is shown in Figure 1d. The first discharge capacity exceeds $900 \mathrm{mAh} / \mathrm{g}_{\mathrm{s}}$ assuming no parasitic reactions, which corresponds to $53 \%$ of the theoretical capacity. Nevertheless, this value is in line with other reports dealing with $A C C / S$ composite electrodes for $\mathrm{Mg} / \mathrm{S}$ system. ${ }^{35,53,54}$ The capacity fading upon cycling is important, with only half of it after the first four cycles. However, the value of $200 \mathrm{mAh} / \mathrm{g}_{\mathrm{s}}$ after 15 cycles is in line with the observation of Manthiram and coworkers with S-CNF composite and a dual-salt electrolyte and with the recent work of Li et al. who used S-infiltrated Ketjen Black conductive carbon and the alkoxyborate-based electrolyte. ${ }^{46,51}$ Post mortem characterization reveals the appearance of a yellowish color on the separators after disassembling the cycled cells that can corresponds to polysulfides diffused/migrated out from the cathode structure (Figure S3). It must be noted that also elemental sulfur is expected to dissolve in the electrolyte with concentrations of a few mmol per liter ${ }^{61}$ and might thus contribute to some extent to the coloring of the separator. Capacity fading can be attributed to a loss of active material from the cathode due to the formation of soluble polysulfides, but no clear polysulfide shuttle is visible in the first two cycles since the charge capacity is constantly lower than discharge capacity. Starting from the third cycle, however, the shuttle effect seems to appear. A more careful investigation of compatibility between calcium metal, polysulfides, calcium salt and solvents needs to be performed in order to better understand such rapid capacity fading which seems to be independent of the polysulfide shuttle effect. In fact, the significant increase of the polarization during the first cycles could be the proof of parasitic reactions at the Ca electrode. 

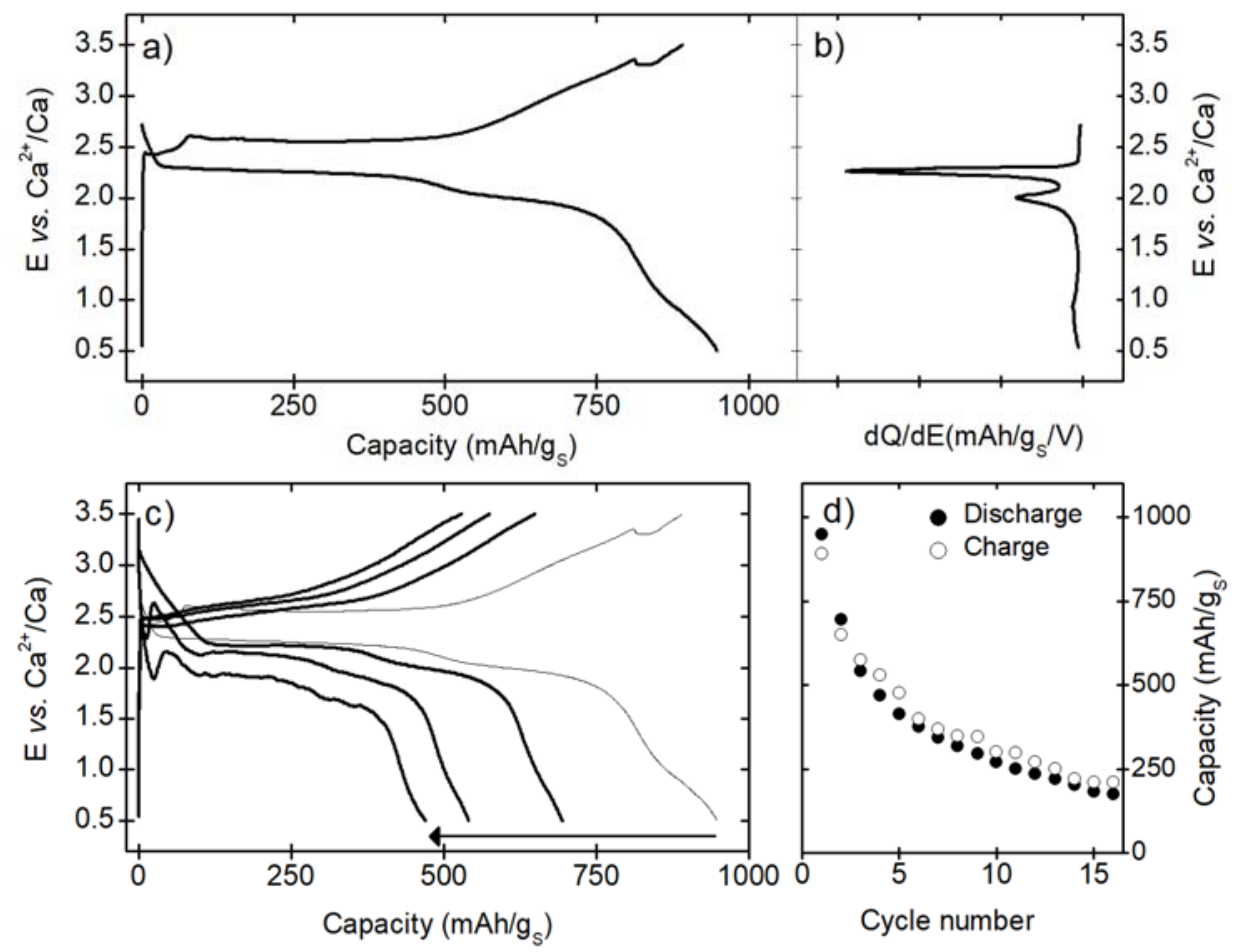

Figure 1: Electrochemical behavior of $\mathrm{Ca} / \mathrm{S}$ cell at $\mathrm{C} / 10$ with $\mathrm{Ca}\left[\mathrm{B}(\mathrm{HFIP})_{4}\right]_{2}$ electrolyte: first discharge and charge profiles (a), derivative curve of the first discharge to highlight the potential plateaus (b), comparison with the subsequent three cycles (c) and capacity retention evolution upon cycling (d).

As already suggested by the coloration of the separator after cycling, the electrochemical reduction of sulfur with calcium ions should induce the intermediate formation on polysulfide species, and the general pathway will drive the galvanostatic profile. ${ }^{30}$ It is also well known for Li/S batteries that the design of the carbon-sulfur positive electrode plays a fundamental role in the voltage profile and in the performance of the cell, and the ACC/S positive electrode proposed in this proof-of-concept cell is not adapted for obtaining the best cycling performance. In fact, in such a simple system the sulfur is not expected to be retained at the cathode side, especially when soluble polysulfide intermediates are formed. Moreover, in this type of positive electrodes, the sulfur content is relatively low (around $10 \mathrm{wt. \% )}$, and such a low value is not adapted to practical applications. Though many different carbon/sulfur composites were tested for preparing this $\mathrm{Ca} / \mathrm{S}$ battery, the best results until now have been obtained with such $\mathrm{ACC} / \mathrm{S}$ composite. Preliminary tests performed with other microporous carbon hosts allowing practical sulfur loadings of the order of $50 \%$ were not satisfying, resulting in the activation of only a very small fraction of the total sulfur (not shown). In particular, it seems that the amount of sulfur in the cell highly influences the electrochemistry, as already observed in the case of $\mathrm{Mg} / \mathrm{S}$ systems. ${ }^{36}$ This phenomenon is not yet well understood, and needs additional investigations. 
In spite of its reduced sulfur loading, the $A C C / S$ system is perfectly adapted for studying the electrochemical mechanism, and especially for the application of in situ X-ray absorption spectroscopy that cannot be carried out in the fluorescence mode using systems with containing higher sulfur fractions. It is also important to mention that the two plateaus observed during the first discharge differ slightly but significantly from those observed in $\mathrm{Mg} / \mathrm{S}$ cells with similar $\mathrm{ACC} / \mathrm{S}$ electrodes. ${ }^{53,54}$

The electrochemical mechanism of this promising proof-of-concept rechargeable $\mathrm{Ca} / \mathrm{S}$ system working at room temperature was investigated by combining two spectroscopic techniques: XPS and XAS. The former allows following the electrochemical activity of sulfur by pointing out the intermediate polysulfide species and by elucidating the end-product of the sulfur reduction, as well as by identifying side reaction products at interfaces. The latter technique was also recently successfully carried out to picture the electrochemical mechanism occurring in $\mathrm{Li} / \mathrm{S}$ or $\mathrm{Mg} / \mathrm{S}$, and adapted in this work for the first time, to the best of our knowledge, for $\mathrm{Ca} / \mathrm{S}$ system. By combining these two characterization techniques, one probing the surface of the samples and the other one the bulk, it is possible to follow the evolution of both sulfur and calcium species in the battery, as well as to obtain additional information about possible decomposition products formed during cycling.

The S 2p, Ca $2 p$ and F 1s XPS spectra of the carbon/sulfur composite electrodes stopped at different points of the first discharge/charge cycle are shown in Figure 2. Additional spectra (B 1s, $O$ 1s and $C 1 s$ ) are plotted in Figure S2 and the quantification data of all spectra are given in Table S1. As important electrochemically active species are soluble in the electrolyte (namely, sulfur and calcium polysulfides $\mathrm{CaS}_{n}$ ) it was decided, the same way as for previous studies carried out on Li-S batteries, ${ }^{62}$ to analyze unwashed samples recovered after opening the cells. This means that a rather high amount of salt may remain at the surface of the electrodes, but also that all the information on dissolved species in the vicinity of the electrode surface (which precipitate at the surface of the electrode during the drying process) as well as insoluble products formed at the surface of the electrode in the battery are preserved. The $S 2 p$ spectrum of the pristine electrode shows the signature of elemental sulfur $\left(2 p_{3 / 2^{-}}\right.$ $2 p_{1 / 2}$ doublet with $2 p_{3 / 2}$ component at $164.0 \mathrm{eV}$ ), together with surface oxidation products, namely sulfite and sulfate, respectively) which cannot be avoided during the impregnation process. Let's recall that the XPS probe depth is about $5 \mathrm{~nm}$, which enhances dramatically the signal of surface species. For the same reason, the measured amount of elemental sulfur is less than expected in the bulk (only 1.3 at.\%). The signals of sulfite and sulfate are also observed after the electrochemical discharge/charge.

During the discharge process, the $S 2 p$ signal of elemental sulfur is gradually and almost completely replaced by two new signals at 162 and $160.5 \mathrm{eV}$, attributed to terminal sulfur atoms in polysulfides $\mathrm{CaS}_{\mathrm{n}}$ and to calcium sulfide CaS, respectively. It must be underlined that the signal of elemental sulfur 
cannot be distinguished from the signature of bridging sulfur atoms in polysulfides. Then, upon charge, CaS and short-chain polysulfides are gradually converted into elemental sulfur and long-chain polysulfides. The observed polysulfides formed at the different electrochemical steps are certainly a mixture of different $\mathrm{CaS}_{n}$ compounds with various chain lengths. Based on XPS data it is possible to estimate the average chain length $n_{a v}$. from the intensity ratio $R_{b / t}$ of the component assigned to bridging sulfur atoms $\left(S_{b}\right)$ to the component assigned to terminal sulfur atoms $\left(S_{t}\right): S_{t}-S_{b}-S_{b}-\ldots-S_{b}-$ $S_{t}$ using the following equation: $n_{a v}=2 \times\left(R_{b / t}+1\right)$. If $\mathrm{CaS}_{2}$ is the only polysulfide present, no bridging $S$ atoms are observed, so $R_{b / t}=0$ and $n_{a v}=2$. Opposite to this, if elemental sulfur is still present in the system together with long-chain polysulfides (at the beginning of discharge, for example) $R_{b / t}$ can be very high and $\mathrm{n}_{\mathrm{av}}>8$. Using this method, after discharge at $2.16 \mathrm{~V}$, a mixture of elemental sulfur and long-chain polysulfides are present since the calculated average chain length is $n_{\text {av. }} \approx 15$. After discharge at $1.79 \mathrm{~V}$, there is a mixture of $\sim 50 \% \mathrm{CaS}$ and $\sim 50 \%$ polysulfides $\mathrm{CaS}_{\mathrm{n}}$ with $\mathrm{n}_{\mathrm{av}} \approx 4$. At the end of discharge $(0.5 \mathrm{~V})$ the electrochemically active species are composed of $\sim 80 \% \mathrm{CaS}$ and $\sim 20 \%$ short-chain polysulfides $\mathrm{CaS}_{n}$ with $\mathrm{n}_{\mathrm{av} .} \approx 2.7$ (therefore, mostly $\mathrm{CaS}_{2}$ and $\mathrm{CaS}_{3}$ ). Finally, after charge at $3.5 \mathrm{~V}$ a mixture of $\sim 8 \% \mathrm{CaS}$ and $\sim 92 \%$ elemental sulfur and long-chain polysulfides are recovered with $\mathrm{n}_{\mathrm{av}} \approx 14$. These compositions are measured in the first $\sim 5 \mathrm{~nm}$-thick layer of the sample, but are also representative of slightly deeper parts of the electrode since dissolved species move to the surface and precipitate on it during the evaporation process of the solvent.

In parallel, the Ca $2 p$ XPS spectrum provides complementary information on the formation of CaS. Actually, Ca $2 p$ peak is a poorly resolved signature for Ca species and gathers several species in an unresolved component ( $\mathrm{Ca} 2 \mathrm{p}_{3 / 2}$ component at $347.7 \mathrm{eV}$ ). But fortunately the signature of $\mathrm{CaS}$ is well separated from all other Ca-containing species present in the system. Indeed, an additional component appears after discharge at $1.79 \mathrm{~V}$ and after full-discharge at $0.5 \mathrm{~V}\left(\mathrm{Ca} 2 \mathrm{p}_{3 / 2}\right.$ at $\left.346.4 \mathrm{eV}\right)$ with a very well respected intensity ratio $\mathrm{Ca} / \mathrm{S}=1$ to the $\mathrm{S} 2 \mathrm{p}$ component of $\mathrm{CaS}$. This attribution is comforted by the literature data on $\mathrm{CaS}$, which indicate that the $\mathrm{Ca} 2 \mathrm{p}_{3 / 2}$ peak of this compound is expected at $346.45 \mathrm{eV} .{ }^{63}$ Moreover, this Ca $2 \mathrm{p}$ component of CaS disappears upon charge (the remaining amount of $\mathrm{CaS}$ is too low). Consequently, this study shows almost complete and reversible conversion of elemental sulfur contained in the pristine electrode into polysulfides $\mathrm{CaS}_{n}$ and $\mathrm{CaS}$ upon discharge and charge. These results can be positively compared to those obtained by Manthiram and co-workers for a mixed Li-Ca/S battery, ${ }^{46}$ and are also comparable to those of Zhao-Karger et al. on a $\mathrm{Mg} / \mathrm{S}$ system using a salt with the same anion. ${ }^{35}$ 


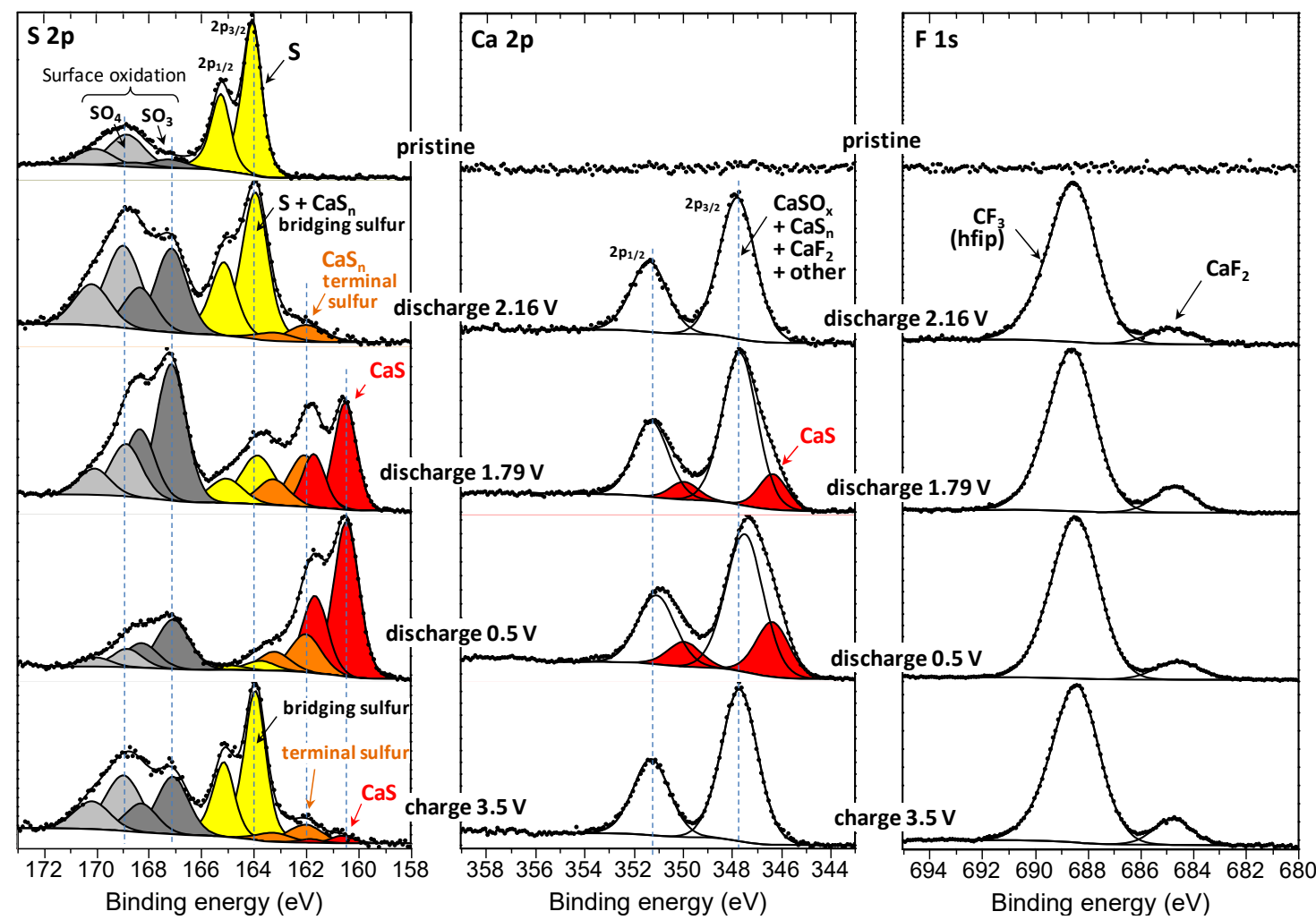

Figure 2. XPS $S 2 p, C a 2 p$ and $F 1 s$ spectra of the $A C C / S$ composite electrodes stopped at different points of the first discharge/charge cycle of a Ca/S battery (unwashed ex-situ samples).

This XPS study also allows the identification of the side reaction products. From the F1s spectra plotted in Figure 2, one can observe, besides the peak attributed to the salt $\mathrm{Ca}\left[\mathrm{B}(\mathrm{hfip})_{4}\right]_{2}$, a small peak assigned to $\mathrm{CaF}_{2}$. This insoluble species formed at the surface of the electrode accounts for 1-3 at.\% of the surface composition. Moreover, by comparing the intensity ratio of the $\mathrm{CF}_{3}$ component ( $\mathrm{F} 1 \mathrm{~s}$ or C 1s) of the salt to the B 1s component (Figure S2), it appears that this ratio is much lower than expected: $\mathrm{C}$ 1s $\left(\mathrm{CF}_{3}\right) / \mathrm{B}$ 1s $\sim 1-2$ instead of 8 for $\left[\mathrm{B}(\mathrm{hfip})_{4}\right]$, and decreases gradually along the first cycle. This means that most of the observed boron is not attributed to the salt but to a decomposition product of it, deposited at the surface of the electrodes. Moreover, looking at the quantitative data of calcium (Table S1), all identified calcium species at the surface, namely the salt $\mathrm{Ca}\left[\mathrm{B}(\mathrm{hfip})_{4}\right]_{2}, \mathrm{CaS}$, $\mathrm{CaS}_{n}, \mathrm{CaF}_{2}$, and even $\mathrm{CaSO}_{3}$ and $\mathrm{CaSO}_{4}$ (assuming sulfite and sulfate are also associated to calcium) are not sufficient to explain the measured amount of calcium. Indeed, from 30 to $50 \%$ of the total observed calcium cannot be explained by the above species. Therefore, it is possible that part of the salt decomposes at the surface of the electrode to form mixed calcium boron oxide species, $(\mathrm{CaO})_{x}\left(\mathrm{~B}_{2} \mathrm{O}_{3}\right)_{y}$, that might play a role in stabilizing the electrode/electrolyte interface thus contributing to the electrochemical efficiency. Nonetheless, it should be again remembered that XPS is a surface- 
sensitive technique and that the amount of this decomposition product is significant in a $5 \mathrm{~nm}$-thick layer at the surface, but contributes only to a very negligible part of the mass of the electrode.
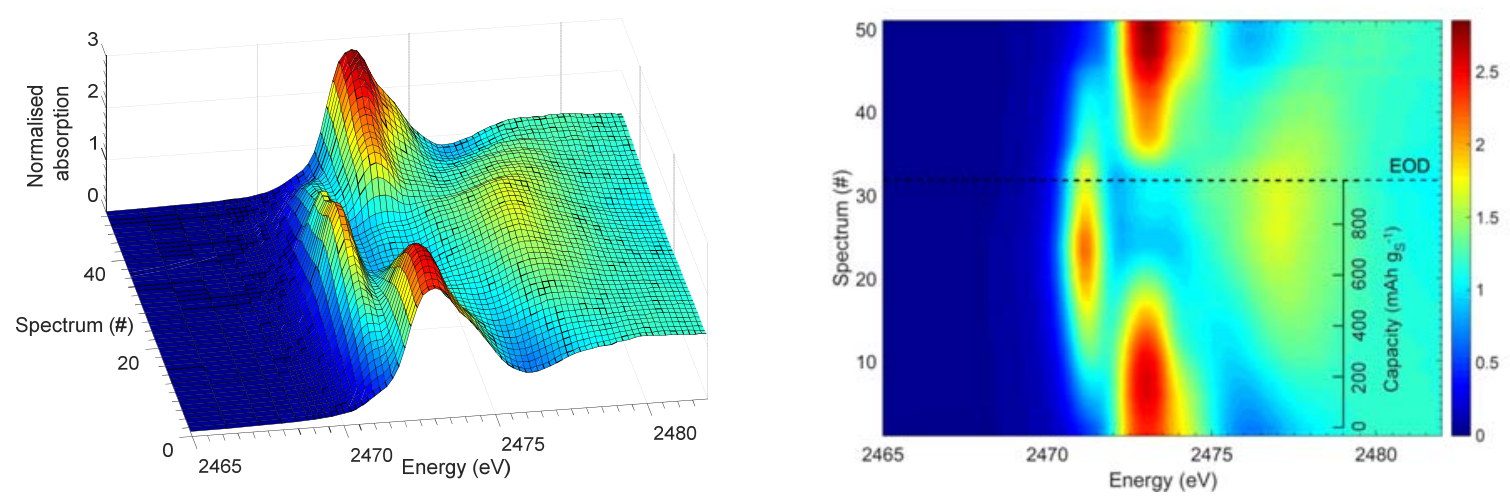

Figure 3. 3D (left) and topographic (right) view of the operando $S K$-edge XANES spectra measured during a full discharge/charge cycle of a $\mathrm{Ca} / \mathrm{S}$ battery. The dashed line in the topographic view indicates the EOD, whereas the last spectrum is measured at EOC. The correspondence between electrochemistry and spectrum \# is given in Figure 54 .

In order to obtain a complementary information by probing the bulk of the electrode, a complementary operando Ca and S K-edge XAS study performed. The operando S K-edge XANES spectra collected on the back of the positive electrode through a full discharge-charge cycle are shown in Figure 3. The electrochemical signature obtained in the in situ cell is much more polarized than the signal in the coin cell, as shown in Figure S4. Such polarization is inherent to the in situ cell setup, which is built with some unavoidable constraints (extremely thin Be window glued to the metal body of the cell) given the low energy X-rays of Ca and especially S K-edge XAS. For this reason, the cell was cycled in a large potential range from 0.5 to $4 \mathrm{~V} \mathrm{vs}$. $\mathrm{Ca}^{2+} / \mathrm{Ca}$, and a floating process at the constant potential of $0.5 \mathrm{~V}$ for 3 hours was added at the end of the discharge to push further the electrochemical reaction. Under these conditions, the reaction of almost 0.6 mole of Ca per mole of $S$ was obtained during the first discharge, while 0.4 mole of $\mathrm{Ca}^{2+}$ were extracted during the subsequent charge. It must be noted that about the same fraction of sulfur reacted in the coin cell experiment (vide supra)

Data analysis was performed on the full set of normalized XANES spectra using a chemometric approach as described in detail in ref. $\left.{ }^{59}\right]$. The full analytical methodology specifically used for analyzing this dataset is described in the SI section. PCA applied to the whole experimental dataset indicated that at least 6 independent spectral components must be used to process it. The spectral components determined by the separate analysis by MCR-ALS of the charge and discharge processes (cf. SI for a detailed description of the procedure) were used as starting points for the MCR-ALS 
analysis of the full cycle. The latter analysis provided the 6 pure spectral components shown in Figure 4 together with the evolution of their concentration during the electrochemical cycle.
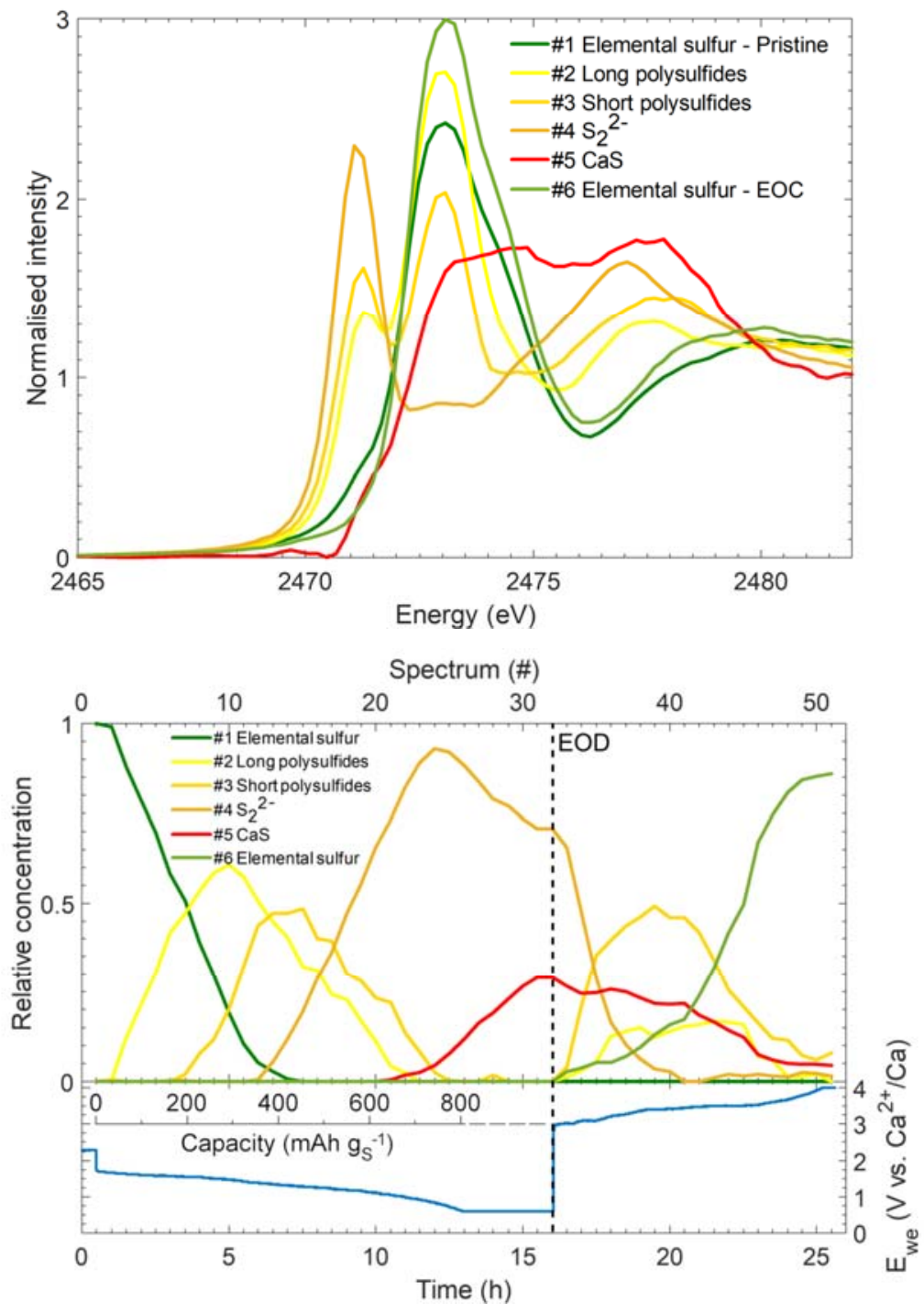

Figure 4. MCR-ALS components (top) and their relative contribution (bottom) to the operando $S K$ edge XANES spectra measured during a full discharge/charge cycle of a Ca/S battery. The

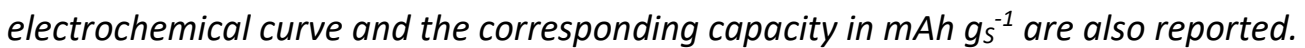

On the basis of the previous XAS studies of the mechanism of Li/S and $\mathrm{Mg} / \mathrm{S}$ systems, ${ }^{36,57,64-72}$ the analysis of the different components is relatively straightforward, allowing a very clear description of the electrochemical mechanism (Figure 4). In fact, the first component (MCR-ALS 1) shows a main peak at $2473 \mathrm{eV}$ with a weak shoulder at $2474 \mathrm{eV}$, as usually observed for plain bulk sulfur $\left(\mathrm{S}_{8}\right)$, which indeed represents the pristine material. During the discharge, this component regularly decreases in intensity and is slowly replaced by two relatively similar components (MCR-ALS 2 and 3) which do not show the shoulder at $2474 \mathrm{eV}$ but present an additional feature at about $2471 \mathrm{eV}$. These two species 
represent calcium polysulfides, and the peaks at 2473 and $2471 \mathrm{eV}$ are usually attributed to chain and terminal sulfur atoms of the polysulfide chain, respectively ${ }^{65,66,73}$ To this regard, component MCRALS 2 stands for longer polysulfides than component MCR-ALS 3 (see SI for more details). Most probably, MCR-ALS 2 represents the first polysulfide formed after the opening of the $\mathrm{S}_{8}$ cycle, i.e., $\mathrm{S}_{8}{ }^{2-}$ , while MCR-ALS 3 corresponds to an intermediate composition or a mixture of different polysulfides between $\mathrm{S}_{8}{ }^{2-}$ and $\mathrm{S}_{2}{ }^{2-}$. No additional feature is observed below $2471 \mathrm{eV}$, indicating that no significant amounts of radical polysulfides are formed in the studied $\mathrm{Ca} / \mathrm{S}$ system. ${ }^{74,75}$

The subsequent component (MCR-ALS 4) exhibits only a main feature at $2471 \mathrm{eV}$, indicating the formation of a (poly)sulfide species containing only terminal sulfur atoms. This component can thus be attributed to the formation of $\mathrm{S}_{2}{ }^{2-}$, the shortest polysulfide before the precipitation of $\mathrm{CaS}$ which is testified by the appearance of component MCR-ALS 5. The latter reaches its maximum intensity (about $25-30 \%$ of the total sulfur) at the end of the discharge, and its attribution to CaS can be done by simply matching it with the spectrum of bulk CaS (Figure S9). It is interesting to notice that by performing appropriate linear combinations of MCR-ALS 2, MCR-ALS 3 and MCR-ALS 4 it is possible to obtain the signature of all other possible polysulfide compositions between $\mathrm{S}_{8}{ }^{2-}$ and $\mathrm{S}_{2}{ }^{2-}$, and that the observed trend clearly testifies the gradual formation of shorter and shorter polysulfides along the discharge.

Interestingly, two different components representing elemental sulfur are found, i.e., component MCR-ALS 1 which represents sulfur in the pristine electrode and component MCR-ALS 6 which testifies the reformation of elemental sulfur upon charge. Slight differences in shape and intensity of the peak at $2473 \mathrm{eV}$ can be attributed to a modification of the self-absorption of sulfur detected in the fluorescence mode, which derives from a decrease of the amount of detected sulfur in the probed part of the sample, i.e., in the back of the ACC/S electrode (cf. Figure S11). This decrease, which continues through the whole discharge and charge processes, testifies the dynamics of the dissolution/migration of sulfur from the back of the electrode to the electrolyte, which is expected for this simple form of cathode materials where polysulfide species are not retained in the vicinity of the carbon support. The use of more sophisticated microporous carbon-based sulfur electrodes, or similar materials able to restrain the diffusion of polysulfides in the electrolyte and the consequent wellknown polysulfide shuttle effect, will be necessary to produce a $\mathrm{Ca} / \mathrm{S}$ viable cell. ${ }^{76-78}$ In any case, such a difference does not seem to be related to the precipitation of a different sulfur polymorph upon charge.

In spite of the very large polarization observed in the in situ experiment, which unfortunately erases the feature of the electrochemical curve, one can try to correlate the different features of the electrochemical curve with the evolution of the sulfur species by assuming that the reaction in the in situ cell follows the same path of that measured in coin cells. This assumption can be done quite safely 
also considering that the first discharge capacities measured in the two cells are very similar. Typically, in Li/S systems, the high voltage plateau is related to the equilibrium between sulfur and polysulfides, whereas the low voltage plateau is related to the equilibrium between polysulfides and solid $\mathrm{Li}_{2} \mathrm{~S}$, the intermediate sloping region being governed by the equilibria between different polysulfide species. ${ }^{79}$ In the case of the $\mathrm{Ca} / \mathrm{S}$ system, during the first discharge in coin cell (Figure 1), an inflection is observed after the reaction at a capacity slightly below $500 \mathrm{mAh} \mathrm{g}^{-1}$, i.e., around spectrum $\# 15$. At this point, the elemental sulfur content detected by XAS goes to $0 \%$, thus comforting the idea that the first plateau corresponds to the equilibrium between sulfur and polysulfides. $\mathrm{CaS}$, on the other hand, appears only at a capacity of $650 \mathrm{mAh} \mathrm{g}^{-1}$, corresponding to the reaction of about $0.4 \mathrm{~mol}$ of $\mathrm{Ca}$, i.e., towards the end of the second plateau. Even though this last result is surprising, one should not forget that the XAS measurement is performed in the back of the electrode, and that some CaS might have formed before on a part of the electrode that is not probed. It is thus not unreasonable to transpose the same mechanism of $\mathrm{Li} / \mathrm{S}$ and $\mathrm{Mg} / \mathrm{S}$ systems to $\mathrm{Ca} / \mathrm{S}$ batteries, with a similar "two plateaus" signature governed by the equilibria between polysulfides and the end-member solid phases, $\mathrm{S}$ and CaS.

Additional insight can be derived from the analysis of the Ca K-edge XANES spectra measured on the in situ cell in its pristine state, at the end of discharge and at the end of charge (Figure S12). The spectrum of the in situ $\mathrm{Ca} / \mathrm{S}$ cell in the pristine state is quite similar to that of the bulk electrolyte salt, and in particular have the same edge position. Differences in the edge shape might come from the different configuration of calcium ions once the salt is dissolved in DME. The spectrum at EOD, however, is shifted towards lower energies, in agreement with the formation of CaS. At end of charge (EOC), the spectrum becomes very similar to that of the pristine state, indicating the disappearance of CaS. In order to quantify the amount of CaS in the measured spectrum, and to evaluate the possible presence of decomposition products, a linear combination fit (LCF) was performed on the salt using some available reference compounds, namely $\mathrm{CaS}$, the $\mathrm{Ca}\left[\mathrm{B}(\mathrm{hfip})_{4}\right]_{2}$ salt and $\mathrm{CaCO}_{3}$ which was chosen among the available compounds to represent a possible Ca-containing decomposition product of the electrolyte species formed in the cell during cycling. The XANES spectrum of $\mathrm{CaCO}_{3}$, in fact, is very similar to that of $\mathrm{CaSO}_{4},{ }^{80}$ and both compounds were detected by XPS. The results of the LCF (detailed in the $\mathrm{SI}$ section) indicate that about $29 \pm 3 \%$ of the calcium in the spectrum at EOD is indeed CaS, and that the subtle evolution of the spectrum at EOD might indeed come from an evolution of the $\mathrm{Ca}$ species in the electrolyte, with the possible formation of decomposition products. 


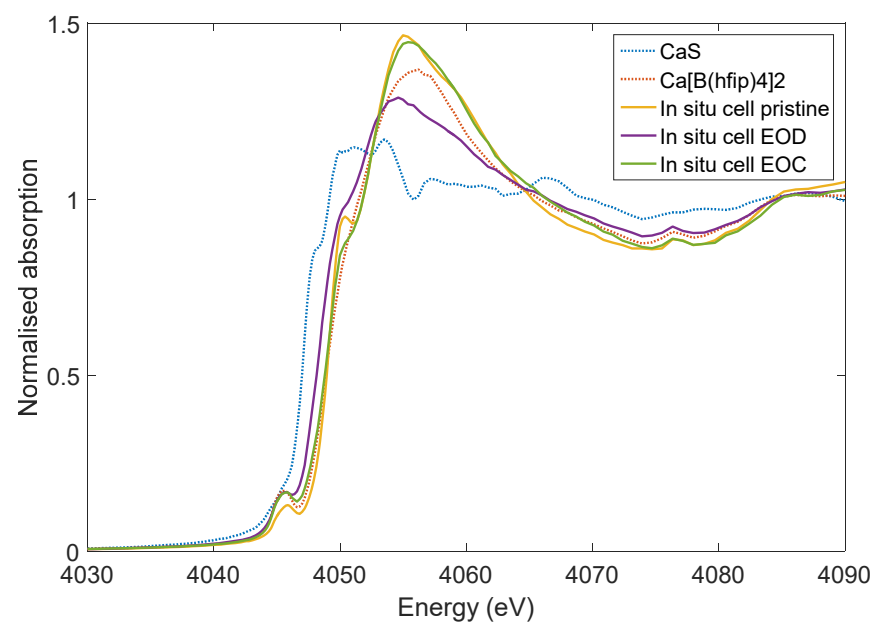

Figure 5. Ca K-edge XANES spectra of the in situ cell measured in the pristine state, at EOD and at EOC compared to selected reference compounds.

By combining the results of both XPS and XAS, it must be first noticed that the mechanism in $\mathrm{Ca} / \mathrm{S}$ batteries strongly resembles that previously observed in $\mathrm{Li} / \mathrm{S}$ and $\mathrm{Mg} / \mathrm{S}$ systems. Until now, however, the capacity fading is still very pronounced, and it might be underlined that no acceptable performance, even for few cycles, could be obtained with higher sulfur loadings. These differences are most probably related to the relative stability of the calcium metal/electrolyte interface, and to the subsequent passivation of the calcium metal surface, but might also be connected to specific issues of metal-sulfur systems, such as the physico-chemical properties (e.g., solubility) of calcium polysulfides, to the ability of polysulfides anions to coordinate reversibly divalent cations, as well as to the possible difficult activation of sulfur and of the discharge products during cycling. A better understanding of such mechanisms is therefore necessary if one wants to move this battery system closer to commercialization. In spite of these negative notes, it must be underlined that the results shown here confirm that it is possible to activate sulfur cathodes in pure-calcium batteries. Such results, even though very preliminary, are thus promising if one considers the potential application of an efficient $\mathrm{Ca} / \mathrm{S}$ battery.

\section{Conclusion}

The very good compatibility of $\mathrm{Ca}\left[\mathrm{B}(\mathrm{hfip})_{4}\right]_{2}$-based electrolytes with sulfur systems is highlighted in this study of a proof-of-concept $\mathrm{Ca} / \mathrm{S}$ battery built using a $\mathrm{ACC} / \mathrm{S}$ positive electrode, in agreement with the results published by Li et al. while this work was at the end of the review process. ${ }^{51}$ The detailed investigation of the electrochemical mechanism carried out by XAS and XPS shows that the reversible conversion of sulfur first to polysulfide species and finally to CaS proceeds at room temperature 
through the two well-defined plateaus, with a consistent part of the sulfur converted into CaS at the end of the first discharge. These reduced sulfur species are then gradually converted back to elemental sulfur during the following charge process, which proceeds through a single plateau followed by a sloping region. Moreover, additional information provided by XPS reveals the deposition of a calciumboron (probably oxide) decomposition product at the surface, which may play a role in the stability of the electrode/electrolyte interface and in the following capacity fading of the battery.

\section{Supporting information}

Supporting information contain additional B 1s, $\mathrm{O} 1 \mathrm{~s}$ and C $1 \mathrm{~s}$ XPS spectra, the complete XPS binding energies, a photo of the separator after cycling, strategy and detailed results of the PCA and MCR-ALS analysis of the operando S K-edge XAS data, the detailed analysis of the in situ and ex situ Ca K-edge XAS data. This material is available free of charge via the internet at http://pubs.acs.org.

\section{Acknowledgements}

This research was performed in the framework of ALISTORE-ERI, which funded the PhD thesis of A. Scafuri. The authors acknowledge the CERIC-ERIC Consortium for the access to experimental facilities at Elettra synchrotron and financial support through project 20192018. The whole staff at beamline XAFS and in particular Luca Olivi are gratefully thanked for expert advice on beamline operation. The Slovenian Research Agency ARRS is acknowledged for the research core funding P2-0393, P1-0112, Z2-1863 and Z2-1864. RB and LS gratefully acknowledge the European Union's Horizon 2020 research and innovation programme for financial support under the grant agreement no. 829145 (FET-Open VIDICAT).

\section{References}

(1) Tarascon, J.-M. Is Lithium the New Gold? Nat. Chem. 2010, 2 (6), 510. https://doi.org/10.1038/nchem.680.

(2) Kawamoto, H.; Tamaki, W. Trends in Supply of Lithium Resources and Demand of the Resources for Automobiles. Sci. Technol. Trends, Quart. Rev. 2011, 39, 51-64.

(3) Thackeray, M. M.; Wolverton, C.; Isaacs, E. D. Electrical Energy Storage for TransportationApproaching the Limits of, and Going beyond, Lithium-Ion Batteries. Energy Environ. Sci. 2012, 5, 7854-7863. https://doi.org/10.1039/c2ee21892e. 
(4) Huang, B.; Pan, Z.; Su, X.; An, L. Recycling of Lithium-Ion Batteries: Recent Advances and $\begin{array}{lllllll}\text { Perspectives. } & \text { J. Power 274-286. }\end{array}$ https://doi.org/10.1016/j.jpowsour.2018.07.116.

(5) Deng, J.; Luo, W.-B.; Chou, S.-L.; Liu, H.-K.; Dou, S.-X. Sodium-Ion Batteries: From Academic Research to Practical Commercialization. Adv. Energy Mater. 2018, 8 (4), 1701428. https://doi.org/10.1002/aenm.201701428.

(6) Kim, S.-W.; Seo, D.-H.; Ma, X.; Ceder, G.; Kang, K. Electrode Materials for Rechargeable Sodium-Ion Batteries: Potential Alternatives to Current Lithium-Ion Batteries. Adv. Energy Mater. 2012, 2 (7), 710-721. https://doi.org/10.1002/aenm.201200026.

(7) Li, Y.; Lu, Y.; Zhao, C.; Hu, Y.-S.; Titirici, M.-M.; Li, H.; Huang, X.; Chen, L. Recent Advances of Electrode Materials for Low-Cost Sodium-Ion Batteries towards Practical Application for Grid Energy Storage. Energy Storage Mater. 2017, 7, 130-151. https://doi.org/10.1016/j.ensm.2017.01.002.

(8) Kundu, D.; Talaie, E.; Duffort, V.; Nazar, L. F. The Emerging Chemistry of Sodium Ion Batteries for Electrochemical Energy Storage. Angew. Chem. Int. Ed. 2015, 54 (11), 3431-3448. https://doi.org/10.1002/anie.201410376.

(9) Eftekhari, A.; Kim, D.-W. Sodium-Ion Batteries: New Opportunities beyond Energy Storage by $\begin{array}{llllll}\text { Lithium. } & \text { J. } & \text { Power } & \text { Sources } & \text { 2018, 336-348. }\end{array}$ https://doi.org/10.1016/j.jpowsour.2018.05.089.

(10) Sawicki, M.; Shaw, L. L. Advances and Challenges of Sodium Ion Batteries as Post Lithium Ion Batteries. RSC Adv. 2015, 5 (65), 53129-53154. https://doi.org/10.1039/C5RA08321D.

(11) Nayak, P. K.; Yang, L.; Brehm, W.; Adelhelm, P. From Lithium-Ion to Sodium-Ion Batteries: Advantages, Challenges, and Surprises. Angew. Chem. Int. Ed. 2018, 57 (1), 102-120. https://doi.org/10.1002/anie.201703772.

(12) Gür, T. M. Review of Electrical Energy Storage Technologies, Materials and Systems: Challenges and Prospects for Large-Scale Grid Storage. Energy Environ. Sci. 2018, 11 (10), 2696-2767. https://doi.org/10.1039/C8EE01419A.

(13) Vaalma, C.; Buchholz, D.; Passerini, S. Non-Aqueous Potassium-Ion Batteries: A Review. Curr. Opin. Electrochem. 2018, 9, 41-48. https://doi.org/10.1016/j.coelec.2018.03.031.

(14) Pramudita, J. C.; Sehrawat, D.; Goonetilleke, D.; Sharma, N. An Initial Review of the Status of Electrode Materials for Potassium-Ion Batteries. Adv. Energy Mater. 2017, 7 (24), 1602911. https://doi.org/10.1002/aenm.201602911.

(15) Xu, Y.-S.; Duan, S.-Y.; Sun, Y.-G.; Bin, D.; Tao, X.-S.; Zhang, D.; Liu, Y.; Cao, A.-M.; Wan, 
L. Recent Developments in Electrode Materials for Potassium-Ion Batteries. J. Mater. Chem. A 2019, 7 (9), 4334-4352. https://doi.org/10.1039/C8TA10953B.

(16) Kubota, K.; Dahbi, M.; Hosaka, T.; Kumakura, S.; Komaba, S. Towards K-Ion and Na-Ion Batteries as "Beyond Li-Ion." Chem. Rec. 2018, 18 (4), 459-479. https://doi.org/10.1002/tcr.201700057.

(17) Eftekhari, A.; Jian, Z.; Ji, X. Potassium Secondary Batteries. ACS Appl. Mater. Interfaces 2017, 9 (5), 4404-4419. https://doi.org/10.1021/acsami.6b07989.

(18) Kim, H.; Kim, J. C.; Bianchini, M.; Seo, D.-H.; Rodriguez-Garcia, J.; Ceder, G. Recent Progress and Perspective in Electrode Materials for K-Ion Batteries. Adv. Energy Mater. 2018, 8 (9), 1702384. https://doi.org/10.1002/aenm.201702384.

(19) Hwang, J.-Y.; Myung, S.-T.; Sun, Y.-K. Recent Progress in Rechargeable Potassium Batteries. Adv. Funct. Mater. 2018, 28 (43), 1802938. https://doi.org/10.1002/adfm.201802938.

(20) Gabaudan, V.; Monconduit, L.; Stievano, L.; Berthelot, R. Snapshot on Negative Electrode Materials for Potassium-Ion Batteries. Front. Energy Res. 2019, 7 (May), 46. https://doi.org/10.3389/fenrg.2019.00046.

(21) Mukherjee, S.; Singh, G. Two-Dimensional Anode Materials for Non-Lithium Metal-Ion Batteries. ACS Appl. Energy Mater. 2019, 2 (2), 932-955. https://doi.org/10.1021/acsaem.8b00843.

(22) Xie, J.; Zhang, Q. Recent Progress in Multivalent Metal (Mg, Zn, Ca, and Al) and Metal-Ion Rechargeable Batteries with Organic Materials as Promising Electrodes. Small 2019, 15 (15), 1805061. https://doi.org/10.1002/smll.201805061.

(23) Muldoon, J.; Bucur, C. B.; Gregory, T. Quest for Nonaqueous Multivalent Secondary Batteries: Magnesium and Beyond. Chem. Rev. 2014, 114 (23), 11683-11720. https://doi.org/10.1021/cr500049y.

(24) Dugas, R.; Forero-Saboya, J. D.; Ponrouch, A. Methods and Protocols for Reliable Electrochemical Testing in Post-Li Batteries (Na, K, Mg, and Ca). Chem. Mater. 2019, 31 (21), 8613-8628. https://doi.org/10.1021/acs.chemmater.9b02776.

(25) Juran, T. R.; Smeu, M. Hybrid Density Functional Theory Modeling of Ca, Zn, and Al Ion Batteries Using the Chevrel Phase Mo6S8 Cathode. Phys. Chem. Chem. Phys. 2017, 19 (31), 20684-20690. https://doi.org/10.1039/C7CP03378H.

(26) Radin, M. D.; van der Ven, A. Stability of Prismatic and Octahedral Coordination in Layered Oxides and Sulfides Intercalated with Alkali and Alkaline-Earth Metals. Chem. Mater. 2016, 28 (21), 7898-7904. https://doi.org/10.1021/acs.chemmater.6b03454. 
(27) Ponrouch, A.; Bitenc, J.; Dominko, R.; Lindahl, N.; Johansson, P.; Palacin, M. R. Multivalent Rechargeable Batteries. Energy Storage Mater. 2019, 20 (April), 253-262. https://doi.org/10.1016/j.ensm.2019.04.012.

(28) Zhao, H.; Xu, J.; Yin, D.; Du, Y. Electrolytes for Batteries with Earth-Abundant Metal Anodes. Chem. Eur. J. 2018, 24 (69), 18220-18234. https://doi.org/10.1002/chem.201802438.

(29) Xu, C.; Chen, Y.; Shi, S.; Li, J.; Kang, F.; Su, D. Secondary Batteries with Multivalent Ions for Energy Storage. Sci. Rep. 2015, 5, 14120. https://doi.org/10.1038/srep14120.

(30) Salama, M.; Rosy; Attias, R.; Yemini, R.; Gofer, Y.; Aurbach, D.; Noked, M. Metal-Sulfur Batteries: Overview and Research Methods. ACS Energy Lett. 2019, 4 (2), 436-446. https://doi.org/10.1021/acsenergylett.8b02212.

(31) Canepa, P.; Sai Gautam, G.; Hannah, D. C.; Malik, R.; Liu, M.; Gallagher, K. G.; Persson, K. A.; Ceder, G. Odyssey of Multivalent Cathode Materials: Open Questions and Future Challenges. Chem. Rev. 2017, $117 \quad$ (5), 4287-4341. https://doi.org/10.1021/acs.chemrev.6b00614.

(32) Kim, H. S.; Arthur, T. S.; Allred, G. D.; Zajicek, J.; Newman, J. G.; Rodnyansky, A. E.; Oliver, A. G.; Boggess, W. C.; Muldoon, J. Structure and Compatibility of a Magnesium Electrolyte with a Sulphur Cathode. Nat. Commun. 2011, 2, 427. https://doi.org/10.1038/ncomms1435.

(33) Zhao-Karger, Z.; Fichtner, M. Beyond Intercalation Chemistry for Rechargeable Mg Batteries: A Short Review and Perspective. Front. Chem. 2019, 6 (January), 656. https://doi.org/10.3389/fchem.2018.00656.

(34) Zhao-Karger, Z.; Gil Bardaji, M. E.; Fuhr, O.; Fichtner, M. A New Class of Non-Corrosive, Highly Efficient Electrolytes for Rechargeable Magnesium Batteries. J. Mater. Chem. A 2017, 5 (22), 10815-10820. https://doi.org/10.1039/C7TA02237A.

(35) Zhao-Karger, Z.; Liu, R.; Dai, W.; Li, Z.; Diemant, T.; Vinayan, B. P.; Bonatto Minella, C.; Yu, X.; Manthiram, A.; Behm, R. J.; et al. Toward Highly Reversible Magnesium-Sulfur Batteries with Efficient and Practical Mg[B(Hfip)4]2 Electrolyte. ACS Energy Lett. 2018, 3 (8), 20052013. https://doi.org/10.1021/acsenergylett.8b01061.

(36) Robba, A.; Vizintin, A.; Bitenc, J.; Mali, G.; Arčon, I.; Kavčič, M.; Žitnik, M.; Bučar, K.; Aquilanti, G.; Martineau-Corcos, C.; et al. Mechanistic Study of Magnesium-Sulfur Batteries. Chem. Mater. 2017, 29 (21), 9555-9564. https://doi.org/10.1021/acs.chemmater.7b03956.

(37) Zhao-Karger, Z. Magnesium-Sulfur Batteries. In Magnesium Batteries: Research and Applications; Fichtner, M., Ed.; The Royal Society of Chemistry: London, UK, 2019; pp 223240. https://doi.org/10.1039/9781788016407-00223. 
(38) Monti, D.; Ponrouch, A.; Araujo, R. B.; Barde, F.; Johansson, P.; Palacín, M. R. Multivalent Batteries-Prospects for High Energy Density: Ca Batteries. Front. Chem. 2019, 7 (FEB), 1-6. https://doi.org/10.3389/fchem.2019.00079.

(39) Chung, S.; Manthiram, A. Current Status and Future Prospects of Metal-Sulfur Batteries. Adv. Mater. 2019, 1901125, 1901125. https://doi.org/10.1002/adma.201901125.

(40) Hong, X.; Mei, J.; Wen, L.; Tong, Y.; Vasileff, A. J.; Wang, L.; Liang, J.; Sun, Z.; Dou, S. X. Nonlithium Metal-Sulfur Batteries: Steps Toward a Leap. Adv. Mater. 2019, 31 (5), 1802822. https://doi.org/10.1002/adma.201802822.

(41) See, K. A.; Gerbec, J. A.; Jun, Y.-S.; Wudl, F.; Stucky, G. D.; Seshadri, R. A High Capacity Calcium Primary Cell Based on the Ca-S System. Adv. Energy Mater. 2013, 3 (8), 1056-1061. https://doi.org/10.1002/aenm.201300160.

(42) Aurbach, D.; Skaletsky, R.; Gofer, Y. The Electrochemical Behavior of Calcium Electrodes in a Few Organic Electrolytes. J. Electrochem. Soc. 1991, 138 (12), 3536-3545. https://doi.org/10.1149/1.2085455.

(43) Ponrouch, A.; Frontera, C.; Bardé, F.; Palacín, M. R. Towards a Calcium-Based Rechargeable Battery. Nat. Mater. 2016, 15 (2), 169-172. https://doi.org/10.1038/nmat4462.

(44) Ponrouch, A.; Palacin, M. R. On the Road toward Calcium-Based Batteries. Curr. Opin. Electrochem. 2018, 9, 1-7. https://doi.org/10.1016/j.coelec.2018.02.001.

(45) Wang, D.; Gao, X.; Chen, Y.; Jin, L.; Kuss, C.; Bruce, P. G. Plating and Stripping Calcium in an Organic Electrolyte. Nat. Mater. 2018, 17 (1), 16-20. https://doi.org/10.1038/nmat5036.

(46) Yu, X.; Boyer, M. J.; Hwang, G. S.; Manthiram, A. Toward a Reversible Calcium-Sulfur Battery with a Lithium-Ion Mediation Approach. Adv. Energy Mater. 2019, 9 (14), 1803794. https://doi.org/10.1002/aenm.201803794.

(47) Li, Z.; Fuhr, O.; Fichtner, M.; Zhao-Karger, Z. Towards Stable and Efficient Electrolytes for Room-Temperature Rechargeable Calcium Batteries. Energy Environ. Sci. 2019, 12 (12), 34963501. https://doi.org/10.1039/C9EE01699F.

(48) Shyamsunder, A.; Blanc, L. E.; Assoud, A.; Nazar, L. F. Reversible Calcium Plating and Stripping at Room Temperature Using a Borate Salt. ACS Energy Lett. 2019, 4 (9), 2271-2276. https://doi.org/10.1021/acsenergylett.9b01550.

(49) Nielson, K. V.; Luo, J.; Liu, T. L. Optimizing Calcium Electrolytes by Solvent Manipulation for Calcium Batteries. Batter. Supercaps 2020, DOI: 10.1002/batt.202000005. https://doi.org/10.1002/batt.202000005.

(50) Nielson, K. V.; Liu, T. L. Dawn of Calcium Batteries. Angew. Chem. Int. Ed. 2020, 59 (9), 3368 
3370. https://doi.org/10.1002/anie.201913465.

(51) Li, Z.; Vinayan, B. P.; Diemant, T.; Behm, R. J.; Fichtner, M.; Zhao-Karger, Z. Rechargeable Calcium-Sulfur Batteries Enabled by an Efficient Borate-Based Electrolyte. Small 2020, DOI: 10.1002/smll.202001806. https://doi.org/10.1002/smll.202001806.

(52) Bitenc, J.; Scafuri, A.; Pirnat, K.; Jerman, I.; Grdadolnik, J.; Berthelot, R.; Stievano, L.; Dominko, R. Electrochemical Performance and Mechanism of Calcium Metal-Organic Battery. Batter. Supercaps 2020, Just accepted (DOI: 10.1002/batt.202000197). https://doi.org/10.1002/batt.202000197.

(53) Gao, T.; Ji, X.; Hou, S.; Fan, X.; Li, X.; Yang, C.; Han, F.; Wang, F.; Jiang, J.; Xu, K.; et al. Thermodynamics and Kinetics of Sulfur Cathode during Discharge in MgTFSI2 -DME Electrolyte. Adv. Mater. 2018, 30 (3), 1704313. https://doi.org/10.1002/adma.201704313.

(54) Gao, T.; Hou, S.; Wang, F.; Ma, Z.; Li, X.; Xu, K.; Wang, C. Reversible S0/MgSx Redox Chemistry in a MgTFSI2/MgCl2/DME Electrolyte for Rechargeable $\mathrm{Mg} / \mathrm{S}$ Batteries. Angew. Chem. Int. Ed. 2017, 56 (43), 13526-13530. https://doi.org/10.1002/anie.201708241.

(55) Meng, Z.; Foix, D.; Brun, N.; Dedryvère, R.; Stievano, L.; Morcrette, M.; Berthelot, R. Alloys to Replace Mg Anodes in Efficient and Practical Mg-Ion/Sulfur Batteries. ACS Energy Lett. 2019, 4 (9), 2040-2044. https://doi.org/10.1021/acsenergylett.9b01389.

(56) Aquilanti, G.; Giorgetti, M.; Dominko, R.; Stievano, L.; Arčon, I.; Novello, N.; Olivi, L. Operando Characterization of Batteries Using X-Ray Absorption Spectroscopy: Advances at the Beamline XAFS at Synchrotron Elettra. J. Phys. D Appl. Phys. 2017, 50 (7), 074001. https://doi.org/10.1088/1361-6463/aa519a.

(57) Dominko, R.; Patel, M. U. M.; Lapornik, V.; Vizintin, A.; Koželj, M.; Novak Tušar, N.; Arčon, I.; Stievano, L.; Aquilanti, G. Analytical Detection of Polysulfides in the Presence of Adsorption Additives by Operando X-Ray Absorption Spectroscopy. J. Phys. Chem. C 2015, 119 (33), 19001-19010. https://doi.org/10.1021/acs.jpcc.5b05609.

(58) Cassinelli, W. H.; Martins, L.; Passos, A. R.; Pulcinelli, S. H.; Santilli, C. V.; Rochet, A.; Briois, V. Multivariate Curve Resolution Analysis Applied to Time-Resolved Synchrotron X-Ray Absorption Spectroscopy Monitoring of the Activation of Copper Alumina Catalyst. Catal. Today 2014, 229, 114-122. https://doi.org/10.1016/j.cattod.2013.10.077.

(59) Fehse, M.; Iadecola, A.; Sougrati, M. T.; Conti, P.; Giorgetti, M.; Stievano, L. Applying Chemometrics to Study Battery Materials: Towards the Comprehensive Analysis of Complex Operando Datasets. Energy Storage Mater. 2019, 18, 328-337. https://doi.org/10.1016/j.ensm.2019.02.002. 
(60) Ravel, B.; Newville, M. ATHENA, ARTEMIS, HEPHAESTUS: Data Analysis for X-Ray Absorption Spectroscopy Using IFEFFIT. J. Synchrotron Rad. 2005, 12 (Pt 4), 537-541. https://doi.org/10.1107/S0909049505012719.

(61) Jeschke, S.; Johansson, P. Predicting the Solubility of Sulfur: A COSMO-RS-Based Approach to Investigate Electrolytes for Li-S Batteries. Chem. Eur. J. 2017, 23 (38), 9130-9136. https://doi.org/10.1002/chem.201701011.

(62) Vizintin, A.; Lozinšek, M.; Chellappan, R. K.; Foix, D.; Krajnc, A.; Mali, G.; Drazic, G.; Genorio, B.; Dedryvère, R.; Dominko, R. Fluorinated Reduced Graphene Oxide as an Interlayer in Li-S Batteries. Chem. Mater. 2015, 27 (20), 7070-7081. https://doi.org/10.1021/acs.chemmater.5b02906.

(63) Briggs, D.; Seah, M. P. Practical Surface Analysis: Auger and X-Ray Photoelectron Spectroscopy; Briggs, D., Seah, M. P., Eds.; Practical Surface Analysis; John Wiley and Sons Ltd.: Chichester, 1990.

(64) Zhao, E.; Wang, J.; Li, F.; Jiang, Z.; Yang, X.-Q.; Wang, F.; Li, H.; Yu, X. Exploring Reaction Dynamics in Lithium-Sulfur Batteries by Time-Resolved Operando Sulfur K-Edge X-Ray Absorption Spectroscopy. Chem. Commun. 2019, 55 (34), 4993-4996. https://doi.org/10.1039/C9CC00485H.

(65) Cuisinier, M.; Cabelguen, P.-E.; Evers, S.; He, G.; Kolbeck, M.; Garsuch, A.; Bolin, T.; Balasubramanian, M.; Nazar, L. F. Sulfur Speciation in Li-S Batteries Determined by Operando X-Ray Absorption Spectroscopy. J. Phys. Chem. Lett. 2013, 4 (19), 3227-3232. https://doi.org/10.1021/jz401763d.

(66) Patel, M. U. M.; Arčon, I.; Aquilanti, G.; Stievano, L.; Mali, G.; Dominko, R. X-Ray Absorption Near-Edge Structure and Nuclear Magnetic Resonance Study of the Lithium-Sulfur Battery and Its Components. ChemPhysChem 2014, $15 \quad$ (5), 894-904. https://doi.org/10.1002/cphc.201300972.

(67) Lowe, M. A.; Gao, J.; Abruña, H. D. Mechanistic Insights into Operational Lithium-Sulfur Batteries by in Situ X-Ray Diffraction and Absorption Spectroscopy. RSC Adv. 2014, 4 (35), 18347-18353. https://doi.org/10.1039/c4ra01388c.

(68) Gorlin, Y.; Siebel, A.; Piana, M.; Huthwelker, T.; Jha, H.; Monsch, G.; Kraus, F.; Gasteiger, H. A.; Tromp, M. Operando Characterization of Intermediates Produced in a Lithium-Sulfur Battery. J. Electrochem. Soc. 2015, $162 \quad$ (7), A1146-A1155. https://doi.org/10.1149/2.0081507jes.

(69) Gorlin, Y.; Patel, M. U. M.; Freiberg, A.; He, Q.; Piana, M.; Tromp, M.; Gasteiger, H. A. Understanding the Charging Mechanism of Lithium-Sulfur Batteries Using Spatially Resolved 
Operando X-Ray Absorption Spectroscopy. J. Electrochem. Soc. 2016, 163 (6), A930-A939. https://doi.org/10.1149/2.0631606jes.

(70) Talaie, E.; Bonnick, P.; Sun, X.; Pang, Q.; Liang, X.; Nazar, L. F. Methods and Protocols for Electrochemical Energy Storage Materials Research. Chem. Mater. 2017, 29 (1), 90-105. https://doi.org/10.1021/acs.chemmater.6b02726.

(71) Dominko, R.; Vizintin, A.; Aquilanti, G.; Stievano, L.; Helen, M. J.; Munnangi, A. R.; Fichtner, M.; Arčon, I. Polysulfides Formation in Different Electrolytes from the Perspective of X-Ray Absorption Spectroscopy. J. Electrochem. Soc. 2018, 165 (1), A5014-A5019. https://doi.org/10.1149/2.0151801jes.

(72) Wang, D. R.; Shah, D. B.; Maslyn, J. A.; Loo, W. S.; Wujcik, K. H.; Nelson, E. J.; Latimer, M. J.; Feng, J.; Prendergast, D.; Pascal, T. A.; et al. Rate Constants of Electrochemical Reactions in a Lithium-Sulfur Cell Determined by Operando X-Ray Absorption Spectroscopy. J. Electrochem. Soc. 2018, 165 (14), A3487-A3495. https://doi.org/10.1149/2.0981814jes.

(73) Pascal, T. A.; Wujcik, K. H.; Velasco-Velez, J.; Wu, C.; Teran, A. A.; Kapilashrami, M.; Cabana, J.; Guo, J.; Salmeron, M.; Balsara, N.; et al. X-Ray Absorption Spectra of Dissolved Polysulfides in Lithium-Sulfur Batteries from First-Principles. J. Phys. Chem. Lett. 2014, 5 (9), 1547-1551. https://doi.org/10.1021/jz500260s.

(74) Cuisinier, M.; Hart, C.; Balasubramanian, M.; Garsuch, A.; Nazar, L. F. Radical or Not Radical : Revisiting Lithium - Sulfur Electrochemistry in Nonaqueous Electrolytes. Adv. Energy Mater. 2015, 5, 1401801. https://doi.org/10.1002/aenm.201401801.

(75) Wujcik, K. H.; Pascal, T. A.; Pemmaraju, C. D.; Devaux, D.; Stolte, W. C.; Balsara, N. P.; Prendergast, D. Characterization of Polysulfide Radicals Present in an Ether-Based Electrolyte of a Lithium-Sulfur Battery During Initial Discharge Using In Situ X-Ray Absorption Spectroscopy Experiments and First-Principles Calculations. Adv. Energy Mater. 2015, 5 (16), 1500285. https://doi.org/10.1002/aenm.201500285.

(76) Ren, W.; Ma, W.; Zhang, S.; Tang, B. Recent Advances in Shuttle Effect Inhibition for Lithium Sulfur Batteries. Energy Storage Mater. 2019, 23 (February), 707-732. https://doi.org/10.1016/j.ensm.2019.02.022.

(77) Rana, M.; Li, M.; Huang, X.; Luo, B.; Gentle, I.; Knibbe, R. Recent Advances in Separators to Mitigate Technical Challenges Associated with Re-Chargeable Lithium Sulfur Batteries. J. Mater. Chem. A 2019, 7 (12), 6596-6615. https://doi.org/10.1039/C8TA12066H.

(78) Xu, J.; Ma, J.; Fan, Q.; Guo, S.; Dou, S. Recent Progress in the Design of Advanced Cathode Materials and Battery Models for High-Performance Lithium-X (X $=\mathrm{O} 2, \mathrm{~S}, \mathrm{Se}, \mathrm{Te}, \mathrm{I} 2, \mathrm{Br} 2)$ Batteries. Adv. Mater. 2017, 29 (28), 1606454. https://doi.org/10.1002/adma.201606454. 
(79) Wild, M.; O’Neill, L.; Zhang, T.; Purkayastha, R.; Minton, G.; Marinescu, M.; Offer, G. J. Lithium Sulfur Batteries, A Mechanistic Review. Energy Environ. Sci. 2015, 8 (12), 3477-3494. https://doi.org/10.1039/C5EE01388G.

(80) Takahashi, Y.; Miyoshi, T.; Yabuki, S.; Inada, Y.; Shimizu, H. Observation of Transformation of Calcite to Gypsum in Mineral Aerosols by Ca K-Edge X-Ray Absorption near-Edge Structure (XANES). Atmos. Environ. 2008, $42 \quad$ (26), 6535-6541. https://doi.org/10.1016/j.atmosenv.2008.04.012. 
ToC graphic

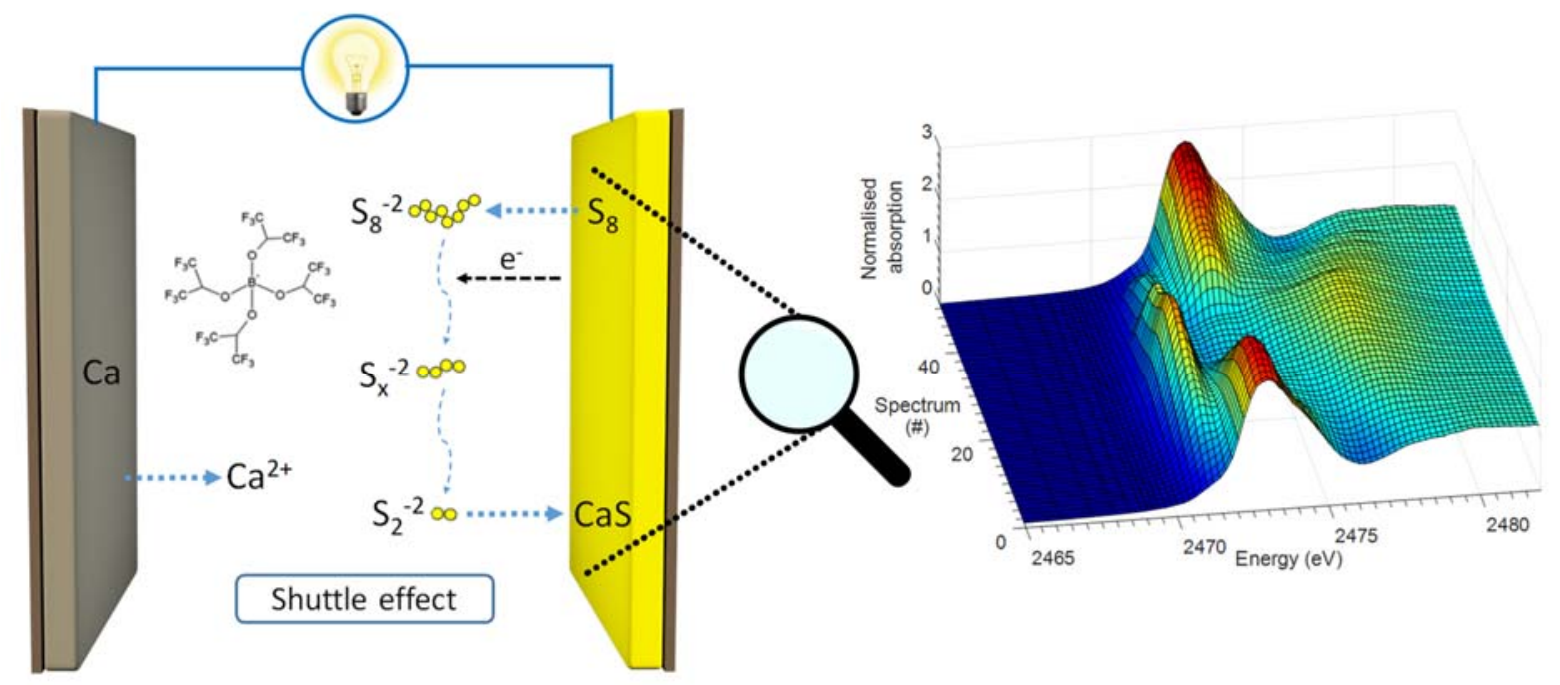

